\title{
RISK FACTORS AND OUTCOMES FOR SEPTIC COMPLICATIONS AFTER LAPAROSCOPIC AP. PENDECTOMY
}

\author{
Konstantin Kostov \\ Department of General, Visceral and Emergency Surgery, UMHATEM "N. I. \\ Pirogov" - Sofia, Bulgaria.
}

\section{SUMMARY}

Purpose: The aim of the study is to investigate the postoperative infectious complications after laparoscopic appendectomy of patients with acute appendicitis in UMHATEM "N.I.Pirogov".

Material and Methods: For a period of one year from 1.1.2018 to 31.12.2018. a total of 218 patients with acute appendicitis were operated in the General, Visceral and Emergency Surgery Department of UMHATEM "Pirogov". Of these, 143 were laparoscopic apendectomy. Indicators characterizing basic clinical and pathological features (epidemiology, demography, degree of pathological disability), surgical approach and outcomes (postoperative complications, duration of the postoperative period) were analyzed.

Results: Of the 143 of the patients- women are 79 $(55.24 \%)$, male $-51(44.76 \%)$. The age of the patients varies from 18 to 79 years. The laparoscopy time interval is 21-117min., and in some cases, with a prolonged operation, the conversions are included. The hospital stay ranged from 2 to 8 days. Postoperative complications were recorded in 13 cases $(9.09 \%)$ - wound infection in nine (treated with VAC dressing), two patients with $(0.92 \%)$ intra-abdominal abscess (PTC drained) and other 2-with ileus (with conservative treatment).

Conclusion: Aggressive manipulations on infected appendix and irregular lavage can spread bacterial contamination. Compliance with standardized laparoscopic appendectomy rules and systematized training of specialists will significantly improve postoperative results.

Keywords: acute appendicitis, laparoscopy, complications, risk factors, infection,

\section{INTRODUCTION}

Nowadays, all over the world, laparoscopic appendectomy is gaining wide acceptance for the diagnosis and treatment of acute appendicitis. For example, the incidence of acute appendicitis is 75 per 100000 from recent data in Canada [1]. Although numerous clinical studies and metaanalyses of data remain debatable whether conventional open appendectomy (OA) or laparoscopic appendectomy (LA) is the most efficient and effective surgical approach in acute appendicitis [2-9].

Laparoscopic appendectomy is established as a safe procedure with its potential advantages of shorter hospital stay, early mobilization, early return of bowel function and acceptable complication rate.

According to analyzes of randomized controlled trials comparing OA and LA, wound infections are half as many in LA, but intra-abdominal abscesses are three times higher. The reasons for more frequent intra-abdominal collections remain debatable. Extensive studies are characterizing the immunological status of patients undergoing laparoscopic surgery, but the results of these were contradictory and clinical conclusions from them regarding the LA remain unclear [10].

The incidence of intra-abdominal abscess is found more common, especially in complicated cases of appendicitis [11].

Literature search has revealed that laparoscopic appendectomy was associated with less postoperative pain and a smaller requirement of postoperative narcotic analgesia.

Clinical experience in UMHATEM "Pirogov" showed no significant increase in postoperative intra-abdominal abscess after laparoscopic appendectomy. An illustration of this is the monitoring and analysis of postoperative complications, in particular, of infectious complications and surgical technique after LA.

\section{MATERIAL AND METHODS}

For one year from 1.1.2018 to 31.12.2018. a total of 218 patients with acute appendicitis were operated on in the General, Visceral and Emergency Surgery Department of UMHALSM "Pirogov". Of these, 143 (65.6\%) were laparoscopic appendectomies.

Table 1. Mode of surgery

\begin{tabular}{|c|c|}
\hline Mode of surgery & 218 \\
\hline conventional appendectomy & $75(34.4 \%)$ \\
\hline laparoscopic appendectomy & $143(65.6 \%)$ \\
\hline
\end{tabular}

In this study, the parameters - age, gender, clinical symptoms, treatment, morbidity and mortality were analyzed. The presence of flushing and pain in the operative wound with data about purulent leakage from the drain- 
age was verified as an intra-abdominal infection. A patient with fever and with symptoms of chills, leukocytosis, ileus, and imaging data (liquid collections depicting an abscess) also was thought to have an intra-abdominal abscess.

There are some differences in the operative technique, so the operative protocols have been thoroughly studied to identify the details that would affect the incidence of postoperative purulent complications.

Other traceable parameters are perioperative antibiotics, a time interval of intervention, contamination of wounds, method of extraction of the appendix, and its pathology.

The data from all patients admitted to the hospital with acute appendicitis were carefully systematized, analyzed, and summarized.

Patients under 18 years of age are not included in this study.

The results are summarized by monitoring the morbidity up to one month post discharge.

\section{RESULTS}

Of the 143 patients- women were $79(55.24 \%)$, male $-51(44.76 \%)$. The age of the patients varied from 18 to 79 years. The laparoscopy time interval was $21-117 \mathrm{~min}$., and in some cases, with a prolonged operative duration, the conversions are included.

The main reasons for this were hemorrhage of mesoappendix, technical causes, adhesions, typhlitis, anatomic variations, bowel lesion susceptibility and cecum cancer- a total of 11 cases $(7.69 \%)$.

Table 2. Reasons for conversion

\begin{tabular}{|c|c|}
\hline Reasons for conversion & $\begin{array}{c}11 \text { cases } \\
(7.69 \%)\end{array}$ \\
\hline hemorrhage of mesoappendix & 2 \\
\hline technical causes & 1 \\
\hline adhesions & 1 \\
\hline typhlitis & 2 \\
\hline anatomic variations & 1 \\
\hline bowel lesion susceptibility & 3 \\
\hline Cecum cancer & 1 \\
\hline
\end{tabular}

In surgical identification, 61 of the patients had phlegmonous appendicitis $(42.66 \%), 55$ with gangrenous appendicitis $(38.46 \%)$, and 19 cases with perforation $(13.28 \%)$. The pathological examination in 7 cases found a normal appendix (4.9\%), and in one of the cases-cecum tumor $(0.7 \%)$.

Table 3. Surgical identification

\begin{tabular}{|c|c|}
\hline Surgical identification & 143 \\
\hline phlegmonous appendicitis & $61(42.66 \%)$ \\
\hline gangrenous appendicitis & $55(38.46 \%)$ \\
\hline
\end{tabular}

\begin{tabular}{|c|c|}
\hline $\begin{array}{c}\text { gangrenous appendicitis } \\
\text { with perforation }\end{array}$ & $19(13.28 \%)$ \\
\hline normal appendix & $7(4.9 \%)$ \\
\hline Cecum cancer & $1(0.7 \%)$ \\
\hline
\end{tabular}

The hospital stay varied from 2 to 8 days.

Postoperative complications were recorded in 13 cases $(9.09 \%)$ - wound infection in nine (treated with VAC dressing), two patients with $(0.92 \%)$ intra-abdominal abscess (PTC drained) and other 2-with ileus (with conservative treatment).

Table 4. Postoperative complications

\begin{tabular}{|c|c|}
\hline Postoperative complications & $13(9.09 \%)$ \\
\hline wound infection & $9(6.29 \%)$ \\
\hline intra-abdominal abscess & $2(1.4 \%)$ \\
\hline Ileus & $2(1.4 \%)$ \\
\hline
\end{tabular}

In 129 patients, antibiotic therapy (90.21\%) was administered, including cases with phlegmonous appendicitis, gangrenous appendicitis, gangrenous appendicitis with intraabdominal abscess, gangrenous perforated appendicitis and with cecum cancer.

Table 5. Mode of treatment

\begin{tabular}{|l|c|}
\hline Mode of treatment & 143 \\
\hline antibiotic therapy & $129(90.21 \%)$ \\
\hline without antibiotics & $14(9.79 \%)$ \\
\hline
\end{tabular}

There are no deaths in both groups-mortality- $0 \%$.

\section{DISCUSSION}

Conclusions from most of the studies on the advantages of LA over OA in the largest hospitals with experienced surgeons and available equipment are undeniable [9]. Concerns about surgical techniques refer to the surgical complications documented after LA and, in particular, the threefold increase in postoperative intra-abdominal abscesses.

In the present study, it was $1,4 \%$, and there was no significant value for infectious complications after LA. The registered patients with intra-abdominal abscess were with gangrenous appendicitis and local sero-fibrinous exudate.

According to some studies, patients with a gangrenous or perforated appendix have an increased risk of intra-abdominal infections, so the laparoscopic approach should not be used [11]. However, with careful tracking of analyzes documenting a high risk of postoperative abscesses, some facts become apparent. In one of the studies, it is emphasized that most laparoscopic appendectomy is performed by young surgeons with little experience in laparoscopy [12].

When laparoscopic intervention violates basic surgical principles, postoperative results are relatively com- 
plicated [13-15]. So far, there has been no clear evidence of an increase in infectious complications after LA. The literature on immunosuppression after laparoscopy is not definite and evidence [10]. Therefore, the reasons for the high frequencies of intra-abdominal abscesses after LA are related to the complicated intraoperative finding and to the way the laparoscopy was performed.

A careful approach to LA and standardization of the procedure can influence infectious complications. The basic surgical principles should be respected and not compromised, especially during the LA training phase. The infected appendix should be trapped with an atraumatic grasper to avoid perforation and subsequent peritoneal contamination. The appendix should be extracted from the peritoneal cavity immediately after transection, taking care not to contaminate the adjacent surfaces or to leak content from its lumen. Protecting the wound from contamination is another important step in which it is recommended that the extraction of the appendix can be accomplished by endobag or another protective device.
Inattentive lavage can also spread the infection to a pelvis or subdiaphragmatic space and thus cause purulent collections [11-15].

\section{CONCLUSION}

According to literature data, the challenges facing LA include a long operating time and increased levels of postoperative infections. However, after analyzing the studies found that the technical implementation of the intervention directly affects the postoperative infectious complications. Aggressive manipulation of the infected appendix and inattentive lavage can spread bacterial contamination. Compliance with standardized rules in LA and systematic training of specialists will significantly improve postoperative outcomes.

\section{Acknowledgement}

This study did not receive any funding. There is no commercial or propriety interest.

\section{REFERENCES:}

1. Al-Omran M, Mamdani MM, McLeod RS. Epidemiologic features of acute appendicitis in Ontario, Canada. Can J Surg. 2003 Aug;46(4):263-8. [PubMed]

2. Golub R, Siddiqui F, Pohl D. Laparoscopic versus open appendectomy: a meta-analysis. J Am Coll Surg. 1998 May;186(5):545-53. [PubMed]

3. Slim K, Pezet D, Chipponi J. Laparoscopic or open appendectomy? Critical review of randomized, controlled trials. Dis Colon Rectum 1998 Mar;41(3):398-403. [PubMed]

4. Chung RS, Rowland DY, Li P, Diaz J. A meta-analysis of randomized controlled trials of laparoscopic versus conventional appendectomy. Am J Surg. 1999 Mar;177(3):250-6. [PubMed]

5. Fingerhut A, Millat B, Borrie F. Laparoscopic versus open appendectomy: time to decide. World J Surg. 1999 Aug;23(8):835-45. [PubMed]

6. Garbutt JM, Soper NJ, Shannon WD, Botero A, Littenberg B. Metaanalysis of randomized controlledtrials comparing laparoscopic and open ap- pendectomy. Surg Laparosc Endosc. 1999 Jan;9(1):17-26. [PubMed]

7. Meynaud-Kraemer L, Colin C, Vergnon P, Barth X. Wound infection in open versus laparoscopic appendectomy. A meta-analysis. Int J Technol Assess Health Care Spring 1999 Spring;15(2):380-91. [PubMed]

8. Temple LK, Litwin DE, McLeod RS. A meta-analysis of laparoscopic versus open appendectomy in patients suspected of having acute appendicitis. Can J Surg. 1999 Oct;42(5):37783. [PubMed]

9. Sauerland S, Lefering R, Neugebauer EA. Laparoscopic versus open surgery for suspected appendicitis. Cochrane Database Syst Rev. 2004 Oct 18;(4):CD001546. [PubMed]

10. Neudecker J, Sauerland S, Neugebauer E, Bergamaschi R, Bonjer HJ, Cuschieri A, et al. The European Association for Endoscopic Surgery clinical practice guideline on the pneumoperitoneum for laparoscopic surgery. Surg Endosc. 2002 Jul;16(7): 1121-43. [PubMed]

11.Yu MC, Feng YJ, Wang W, Fan
W, Cheng HT, Xu J. Is laparoscopic appendectomy feasible for complicated appendicitis? A systematic review and meta-analysis. Int J Surg. 2017 Apr; 40:187-197. [PubMed]

12. Del Pino C, Muñoz R, Rada G. Laparoscopic versus open appendectomy for complicated appendicitis. Medwave. 2018 Dec 11;18(8):e7370. [PubMed]

13. Talha A, El-Haddad H, Ghazal A-E, Shehata G. Laparoscopic versus open appendectomy for perforated appendicitis in adults: randomized clinical trial. Surg Endosc. 2020 Feb; 34(2):907-914. [PubMed]

14. Delibegoviæ S, Karabeg R, Simatoviæ M. Securing the base of the appendix during laparoscopic appendectomy. Med Glas (Zenica). 2020 Aug 1;17(2):252-255. [PubMed]

15. Siotos C, Stergios K, Prasath V, Seal SM, Duncan MD, Sakran JV, et al. Irrigation Versus Suction in Laparoscopic Appendectomy for Complicated Appendicitis: A Meta-analysis. J Surg Res. 2019 Mar;235:237-243. [PubMed]

Please cite this article as: Kostov K. Risk factors and outcomes for septic complications after laparoscopic appendectomy. J of IMAB. 2021 Oct-Dec;27(4):4084-4086. DOI: https://doi.org/10.5272/jimab.2021274.4084

Address for correspondence:

Konstantin Kostov, MD, PhD

Surgical Clinic, UMHATEM "N. I. Pirogov"

21, Totleben Blvd., 1606 Sofia, Bulgaria.

E-mail: dr.k.kostov@gmail.com 